\title{
Understanding, managing and communicating geomechanical mining risk
}

\author{
J Hadjigeorgiou University of Toronto, Canada
}

\begin{abstract}
This paper addresses issues related to understanding, managing and communicating geomechanical mining risk at all decision levels of a mining company. The focus is on how different risk analysis tools and procedures can be used effectively, while also highlighting limitations of some of the most popular tools. A strong case is made for a critical assessment of the effectiveness of risk-management tools. Finally, the paper discusses the challenges of understanding and communicating geomechanical mining risk, given the asymmetry of knowledge and information by decision-makers in mining companies.
\end{abstract}

Keywords: geomechanical mining risk, underground and surface mining, risk tools, asymmetry of knowledge

\section{$1 \quad$ Introduction}

Mining, like any business, is exposed to a multitude of risks. Financial risk is associated with any mining investment, with the possibility that the actual return on an investment will be different from its expected return. Mining companies have to manage traditional financial risks that include credit, liquidity, market, foreign exchange, interest and commodity prices. Furthermore, they have to tackle environmental, community, political and reputation risks in an interconnected global economy. In this context, operational and engineering geomechanical risks are only two of the risks that need to be managed and communicated to the different levels of decision-makers.

Risk implies a possibility that an event may occur and that, if it did, would result in an adverse consequence such as injury, harm or other unwanted effects. Risk management is defined in International Organization for Standardization (ISO 2018) as "coordinated activities to direct and control an organisation with regard to risk". In this context, risk is defined as an "effect of uncertainty on objectives", where an effect is a deviation from the expected. It can be positive, negative or both, and can address, create or result in opportunities and threats.

There are a multitude of geomechanical risks in mining that have to be taken into consideration and accounted for during the scoping, feasibility and operation stages. The mine plan and the company objectives require that the ore resource and geotechnical models perform as predicted to meet productivity goals in a cost-efficient way. In an operating mine, geomechanical risk is often associated with operational goals, as well as health and safety considerations. In all cases, it is necessary to have access to risk-management skills, leadership, and human capital to develop and implement an effective risk-management strategy.

The fundamentals of risk analysis specific to geotechnical and rock engineering or geomechanics have been addressed in a number of publications (e.g. Einstein 1996; Baecher \& Christian 2003). It is recognised that the results of geomechanical risk assessments are treated differently in the decision-making process for mining, compared to civil infrastructure engineering projects. For example, there is a higher degree of conservatism in design of infrastructure projects prone to multiple hazards owing to their long-term nature and access by the public. In comparison, the useful life of mining projects is shorter and personnel exposure is restricted.

The objective of this paper is to contribute towards understanding, managing and communicating geomechanical mining risk at all levels of a mining company. In practice, a major issue in managing geomechanical mining risk is what I would like to define as 'asymmetry of knowledge'. This implies that the 
there is significant variation in the level of information available to the various interveners in the process and in the ability to understand, process and interpret the available information.

This paper focuses on geomechanical risks in underground and surface hard rock mines, realising that these have an impact on other company risks. These include, but are not restricted to, risks associated with workplace safety, high-stress environments and slope stability. These can result in degradation of the mine infrastructure, a threat to mine worker safety, potential loss of life, equipment damage or loss of production.

\section{Analysis of geomechanical mining risk}

A description of probabilistic and reliability analysis tools is beyond the scope of this paper. A comprehensive review of these techniques, as applied to geotechnical engineering, has been provided by Baecher and Christian (2003). There are several definitions of risk. Einstein (2003) notes that risk is often defined as:

$$
\text { Risk }=\mathrm{P}(\text { Loss }) \times \text { Worth of Loss }
$$

where:

$\mathrm{P}($ Loss $)=$ probability that loss occurs.

In a mining context, loss can mean slope failure, and the implication of a flatter slope will have to be accounted for with additional excavation cost.

Baecher and Christian (2003) define risk as the product of probability and consequence:

$$
\text { Risk }=(\text { probability } \times \text { consequence })=(p c)
$$

When more than one event may lead to an adverse outcome, Equation 2 is extended to be the expectation of consequence over that set of events:

$$
\text { Risk }=\sum_{i} p_{i} c_{i}
$$

where:

$$
\begin{aligned}
& I=\text { a set of mutually exclusive scenarios or events } i=1 \ldots n . \\
& p_{i}=\text { probability associated with each element. } \\
& c_{i} \quad=\text { consequences associated with each element. }
\end{aligned}
$$

Einstein (2003) suggested that Equation 1 can also be represented as:

$$
\text { Risk }=\mathrm{P}[\mathrm{U}] \times \text { Consequence }
$$

where:

$\mathrm{P}[\mathrm{U}]=$ probability of unsatisfactory performance.

Consequence can be expressed in financial or other terms.

Noting that it is not always certain the occurrence of unsatisfactory performance will provide consequences (e.g. a rock block may fail from a slope but not always produce damage), Einstein (2003) suggested the following formulation:

$$
\text { Risk }=\mathrm{P}[\mathrm{U}] \times \mathrm{P}[\text { Consequence } \mathrm{I} \mathrm{U}] \times \text { Consequence }
$$

where:

$\mathrm{P}[$ Consequence $\mathrm{IU}]=$ conditional probability expressing the so-called vulnerability.

This formulation was further extended to include both cost and non-cost consequences.

Risk analyses can be used to compare different alternatives, prioritise risks and help in making informed decisions. To these purposes, there are several analytical tools available. Geomechanical risk management has both economic and safety implications for a mining operation. 


\subsection{Surface versus underground geomechanical mining risk}

It is a matter of fact that the management of geomechanical risk in surface mines is more advanced than in underground mines. Surface geomechanical problems are arguably less complex and large-scale events, or slope instability conditions, are often easier to understand and quantify. As illustrated in the work of Steffen (1997), it is also easier to quantify the economic consequences of different geotechnical choices.

A reason for the more advanced stage of geomechanical risk management in open pits is that surface mine instability and impact on the surrounding environment is well monitored. The impact of instability is visible from air/satellite and this information is usually accessible to the public. In the era of omnipresent social media, this can focus attention on any surface instability events, creating a sense of urgency for mining companies. The influence of access to information is illustrated in the Bingham Canyon slope failure of 10 April 2013, which displaced 150 Mt of material down the northeastern pit wall (Figure 1). Within minutes of the incident, images were readily available on multiple media platforms. In contrast, mining companies have greater control over the distribution of images associated with ground failures such as rockburst in actively seismic underground mines.

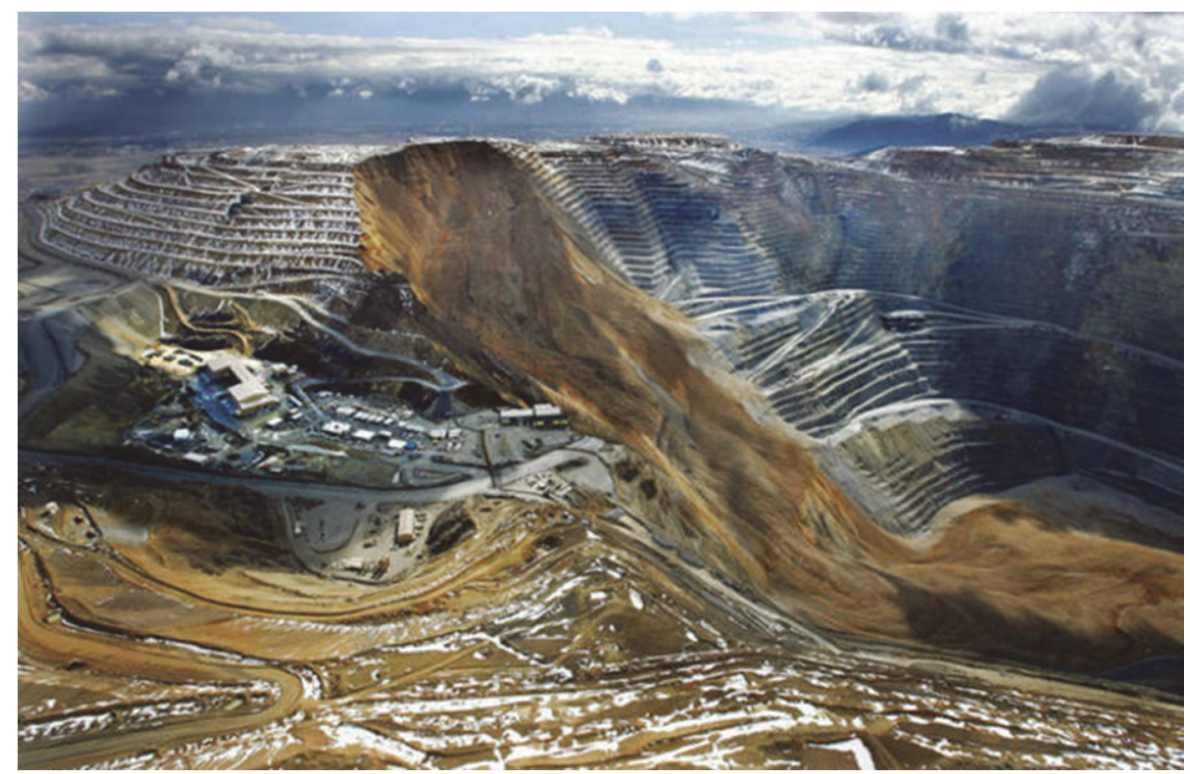

Figure 1 Northeastern pit wall of Kennecott Utah's Bingham Canyon slope instability, Copyright 2018 Rio Tinto

\section{Geomechanical decision analysis}

Geomechanical risk analysis is not an objective in itself but is part of the decision process. Although there are variations, it is generally accepted that the decision process includes a geotechnical data collection stage, analysis, updating and decision-making. All these stages are subject to a degree of uncertainty. Kiureghian and Ditlevsen (2009) differentiated between aleatory and epistemic uncertainty. An aleatoric uncertainty is one that is presumed to be the intrinsic randomness of a phenomenon, and epistemic uncertainty is one that is presumed as being caused by lack of knowledge (or data). Hadjigeorgiou and Harrison (2011) provided rock engineering examples of both types of uncertainty with reference to in situ stress measurements, geomechanical data collection and design tools.

\subsection{Geomechanical data}

The requirements for quality geomechanical data is self-evident. It is difficult to foresee how analysis and design can be successfully accomplished in the absence of reliable data (Hadjigeorgiou 2012). The reality, however, is that it is not possible to eliminate geotechnical uncertainty. Consequently, it is important to recognise, quantify and reduce geotechnical uncertainty, and explicitly account for it in the design process. 
Rock masses are subject to both spatial and temporal variability. Discrete fracture networks (DFNs) are a powerful tool to capture the spatial variability of rock fractures (Dershowitz \& Einstein 1988; Grenon \& Hadjigeorgiou 2003; Rogers et al. 2009). Fillion and Hadjigeorgiou (2018) employed DFN to develop recommendations on the minimum number of orientation data from geotechnical drilling to meet targeted confidence levels. This is a prerequisite in quantifying and minimising uncertainty.

Another important element in mining geomechanics is the availability and confidence in laboratory data. In practice, the sources of error are quantified and potentially reduced by using well-calibrated testing equipment, appropriate sensors and following standard testing procedures such as the International Society for Rock Mechanics suggested methods (Ulusay \& Hudson 2007). Another challenge is determining the number of samples necessary to meet a predefined level of confidence in the results (Gill et al. 2005). An example of these challenges has been presented by Fillion and Hadjigeorgiou (2017) who analysed the uniaxial intact rock test results at a South African mine from feasibility to operation. It has been demonstrated that for a given rock and test type, the minimal sample size varies from one rock type to another (Figure 2). This is significant in that it also highlights that a high confidence interval $(\mathrm{Cl})$ may require a much greater sample size (i.e. number of rock specimens) than suggested by Ulusay and Hudson (2007).

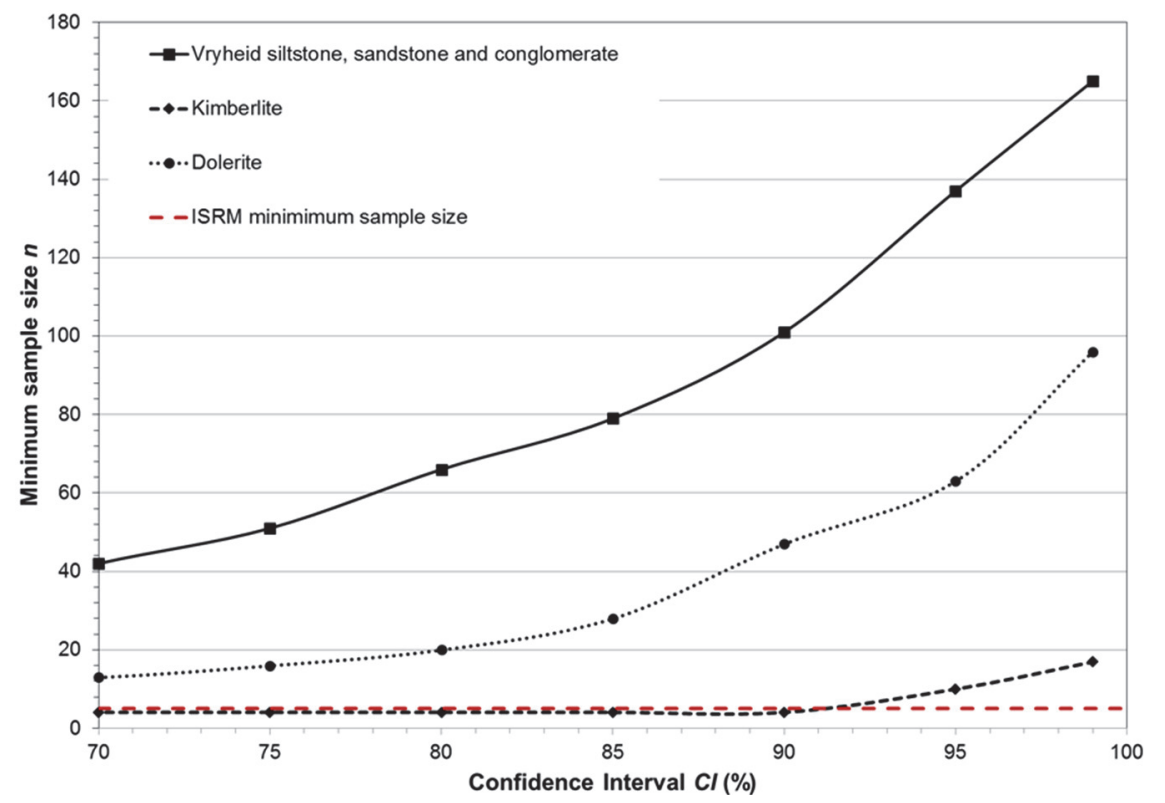

Figure 2 Minimum number of specimens required for a given confidence interval (after Fillion \& Hadjigeorgiou 2017)

It follows that failure to understand the impact of sampling frequency on resulting $\mathrm{Cls}$ has a direct implication on the quality of subsequent engineering analysis and design.

\subsubsection{Empirical design}

Empirical design methods based on rock mass classification systems are widely used in geomechanical mine design. Although the limitations of these systems have been well documented, this has not prevented their widespread use as direct or indirect input to more sophisticated analyses. It is therefore critical to recognise the inherent uncertainty with rock mass classification tools and their impact on geomechanical risk analysis.

A fundamental requirement for the use of most rock mass classification systems is that the rock mass contains a sufficient number of randomly oriented fractures so that it can be treated as a homogeneous isotropic mass. Consequently, rock mass classification systems may be inappropriate for rock masses with dominant structural orientations such as foliation and intrusions (Figure 3 ). 

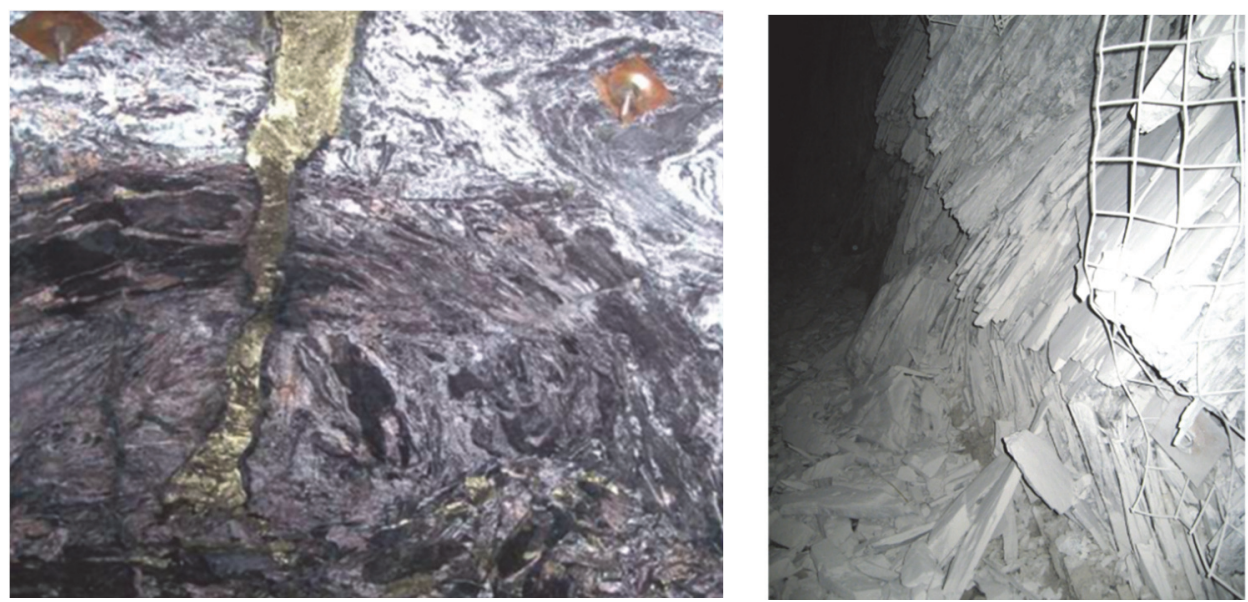

Figure 3 Examples of ground conditions that do not meet the assumption of a homogeneous isotropic rock mass

It is perhaps instructive to differentiate between errors specific to the rock mass classification system employed and errors of implementation (Hadjigeorgiou \& Harrison 2011). In the first category, irrespective of the choice of a classification system, there are errors of omission (i.e. failure to account for pertinent characteristics), errors of superfluousness (i.e. not mutually independent parameters), and errors of taxonomy that result from the requirement to select a particular classification rating value for a geomechanical property. Implementation errors include errors of circumstance (e.g. accessibility and poor visibility), and convenience such as inadequate or insufficient resources. The other source of error is associated with ignoring variability and uncertainty.

\subsubsection{Numerical modelling}

A detailed review of numerical models is beyond the scope of this paper. Critical decisions on whether the rock mass is to be treated as a continuum or a discontinuum, the problem captured as 2D versus 3D, and linear versus non-linear, are often driven by user preference and time constraints. The question whether the model captures the mechanics of the problem and the availability of quality data is sometimes obscured.

Bahrani and Hadjigeorgiou (2018) documented the comparative efforts to calibrate sophisticated continuum and discontinuum models in an underground mine. They discussed that although discontinuum methods may provide better calibrated models compared to continuum methods, due to their higher degrees of freedom arising from greater number of input parameters, may suffer from lack of data to be used as input parameters. Therefore, multiple combinations of input parameters may result in an equivalently well-calibrated but not unique model, raising a concern on their appropriateness as a predictive tool for forward modelling.

A complex model is not necessarily better or more accurate, as all numerical models are also a source of uncertainty. The tendency to tackle model uncertainty by trying to develop more detailed and complex models has its limitations. Invariably, sophisticated or multi-parameter models result in each parameter being susceptible to both spatial variability and measurement errors. Einstein (2003) summarised this dilemma by pointing out that "...what one gains by reducing model uncertainty, one may in turn lose by increased parameter uncertainty".

Wiles (2006) has provided a rigorous template for evaluating the reliability of model predictions. It is evident that such an approach is not routinely applied at most sites. Instead, mines focus on developing calibrated models, where the threshold for reliability is much lower. Wiles (2006) has suggested that "...with realistic time constraints and a limited budget, there is clearly more value in predictions from a well-calibrated simple model, than from an inadequately calibrated complex model with unknown or poorly characterised reliability". 
It is the author's opinion that numerical models have a very important role in understanding and possibly quantifying geomechanical hazards. However, this should not prevent us from recognising the challenges in calibrating models and the need for documenting the process, if a model is to be used for decision-making. This inherent model and data uncertainty is often overlooked when recommendations, based on the results of numerical models, are used for design decisions and in identifying areas of elevated hazards. A step often missing in risk assessment is model evaluation aiming to determine with what level of confidence a decision-maker can rely upon the results of a model. This is critical given that quite often decision-makers do not possess the expertise to assess the quality of the recommendations of numerical models.

\subsubsection{Probabilistic analysis}

The analysis of risk models is well developed and makes use of Probability of Failure (PoF), quantifying uncertainties, and engineering judgment. For a variety of reasons, geomechanical risk is more widely applied to open pit as opposed to underground mines, where the consequences of an event (monetary, personnel) are easier to quantify.

Probabilistic analyses are arguably the most popular quantitative risk techniques and the theory well documented (e.g. Baecher \& Christian 2003). Priest and Brown (1983) provide an early example of probabilistic approaches for open pit mines including acceptability criteria. A number of authors have discussed slope risk management (e.g. Steffen 1997; Terbrugge et al. 2006). Furthermore, there are several examples of stochastic modelling for slope applications that arguably provide powerful tools in quantifying hazards that can be used in a risk-management process.

Probabilistic analyses usually employ representative distributions. Brown (2012) has cautioned that the common assumption that geotechnical variables are normal distributions may not always be justified. This was recognised by Fillion and Hadjigeorgiou (2017) who extended small-sampling theory to capture both normal and lognormal distributions.

It should be reiterated that the quality of probabilistic-based risk analysis relies on the availability of quality geotechnical data. Fillion and Hadjigeorgiou (2016) illustrated the implications of collecting additional data for slope design by undertaking a series of stability analyses over many years of an open pit operation in South Africa. It was shown that collecting additional geomechanical data may sufficiently reduce the uncertainty associated with data variability to support the decision of selecting less conservative slope angles.

Stochastic models are less widely used in underground mining but DFN applications have been available for some time now (e.g. Dershowitz \& Einstein 1988). The use of DFN models for assessing and quantifying instability hazards and the impact of ground support has been presented by Grenon and Hadjigeorgiou (2003), and Hadjigeorgiou and Grenon (2017). Recent work by Joughin et al. (2016) is of interest in that it provides a comprehensive, albeit preliminary, risk-based approach to ground support design addressing both mechanisms of block failure and stress damage, and utilises probabilistic techniques and a damage loss model to quantify risk.

\subsubsection{Risk consequence approach}

Traditional geotechnical slope design aims to provide stable slope configurations to mine planning. A risk consequence approach requires that management decides a priori, risk criteria for an operation (Terbrugge et al. 2006). The decision process should take into consideration the consequences of potential failures, or the benefit of steeper slopes at higher risk. The implication is that slope failures are acceptable provided risks to personnel, equipment damage, economic impact, force majeure, industrial action and negative public relations are within management-defined criteria. Figure 4 illustrates a fault tree for calculating the PoF and the event trees for determining the risk exposure that follows from the selection of a specific slope design against management defined criteria. A similar risk evaluation template has been proposed for stope design (Stacey et al. 2007). 


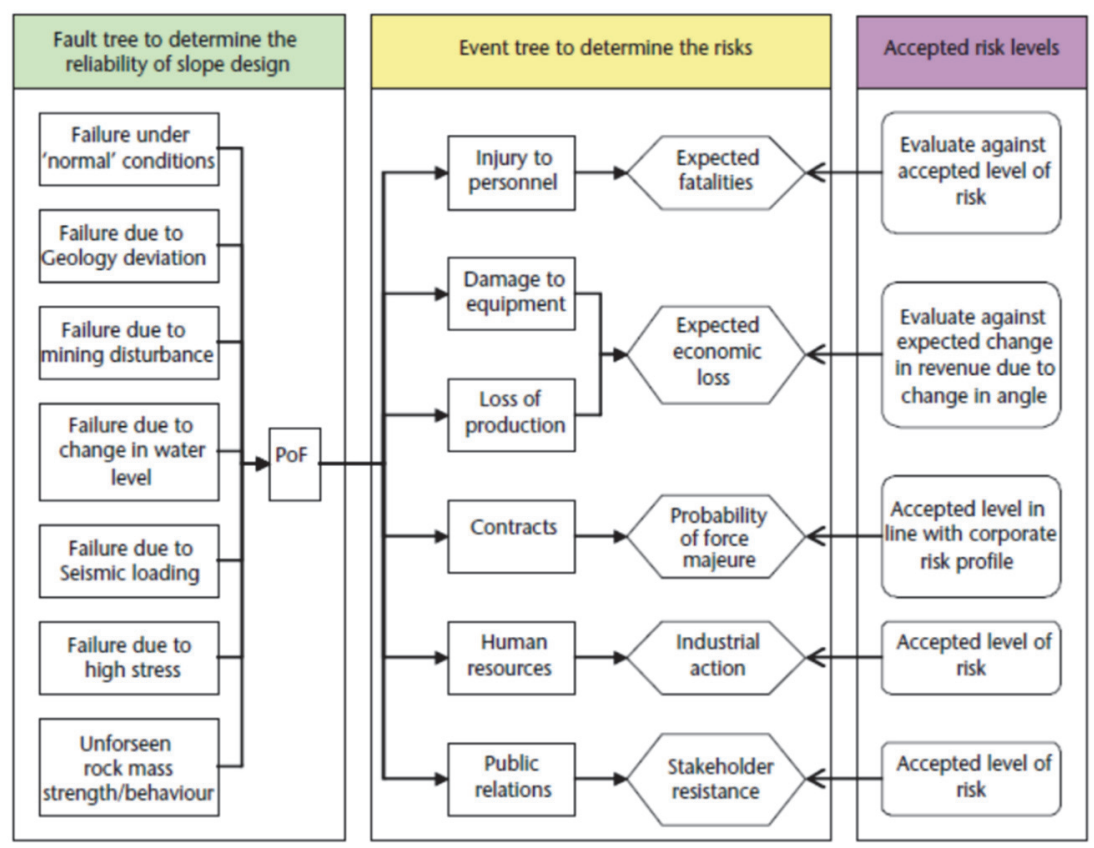

Figure 4 A risk-evaluation process combining fault and event tress for an open pit (after Terbrugge et al. 2006)

The main implication of this approach is that critical decisions for acceptable design rests with mine management and not with geomechanical engineers. This approach has been successfully implemented in feasibility projects, slope steepening for operating mines and design (Steffen et al. 2008).

\section{Tools to administer the geomechanical risk-management process}

It is becoming standard practice to have a corporate risk-management strategy in place. This process has been driven from financial requirements and standards organisation (e.g. ISO 2018). Nevertheless, it is now implicitly or explicitly extended to all elements of mining. In this context, a mining company may require that there is a demonstrated compliance in all operational and engineering activities including geomechanical risk. In certain mining jurisdictions, it is now a legislative requirement for mines to demonstrate compliance to regulatory obligations regarding risk assessments.

\subsection{Risk register}

In general, a risk register identifies the consequences of an event. It is used to identify and clarify ownership of risks and how risks are to be allocated and controlled. It is expected that risk registers provide the basis to develop and implement systems to manage and mitigate risks through contingency measures and controls. It is anticipated that risks and the effectiveness of mitigation measures are to be monitored.

Risk registers are now embedded in mining culture and often mining operations develop detailed lists based on input from several people. This approach is seen as useful as it encourages engagement of multiple stakeholders. Geomechanical risk may be part of an overall risk register. In an underground mine, risk review in Ontario mines ground control was identified as the highest risk category with rockbursts named as the highest risk situation that could result in injury (Gritziotis 2015).

It is surprising that risk register quality is not usually addressed or challenged. In fact, there are potentially considerable pitfalls in the use of risk registers in the decision process. An example is the selection of the contributors to developing a risk register, where often the goal is to include as many participants as possible. It should be recognised that input from numerous participants, with lack of training in risk assessment, can potentially result in confusing and inconsistent wording in a risk register. 
In practice, there are several ways to represent uncertainties in a risk register and it is often difficult to capture links between risks. Another major limitation in gaining value from a risk register is failing to recognise that risks are dynamic as opposed to static. In this context, maintaining a risk register is a continuous process where it is necessary to track the evolution of risk, as well as the impact and effectiveness of risk mitigation actions. The point made in this paper is not that risk registers are of limited value but rather that it is necessary to critically review and assess risk register quality. Failing to do so would result in creating an administrative compliance tool rather than prioritising and addressing important issues.

\subsection{Risk matrix}

Risk matrices are widely used by mining companies and at mine sites as part of an overall risk-management approach and communication strategy. In fact, certain mining companies have now implemented a policy that workers undertake a risk assessment prior to any activity, including installation of ground support. This approach is touted as an integral part of developing and implementing a risk-management culture and worker engagement. The drive towards the use of risk matrices has been recommended by both national, international and corporate organisations where risk matrices are considered part of best practice. The case is often made that the use of risk matrices improve communications. Risk matrices are sometimes used to provide guidance to employees on what is acceptable. Low level risks are usually acceptable without any management involvement, while medium risk would require that management needs to be actively involved to ensure the risk is kept under control.

In effect, a risk matrix is a two-dimensional representation of the relationship between likelihood and consequence or impact. These are assigned to ranges of equal risk (e.g. high, medium or low risk), and are often allocated colours (e.g. red for the highest risks to green for the lowest giving risk), hence the use of the term 'heat map'.

An example of a qualitative risk activity card used in an underground hard rock mine is shown in Figure 5. Miners are expected to complete the card prior to any activity, including tasks related to installation of ground support. This is an effective communication strategy in that it raises awareness and miners are asked to consider the impact on mitigation strategies and effective controls to reduce risk.

\begin{tabular}{|c|c|c|c|c|c|}
\hline \multirow[t]{2}{*}{ Likelihood } & \multicolumn{5}{|c|}{ Consequences } \\
\hline & Minimal & First aid & $\begin{array}{l}\text { Medical } \\
\text { treatment }\end{array}$ & Lost time & Disability \\
\hline Almost certain & Low & Moderate & High & High & High \\
\hline Likely & Low & Moderate & High & High & High \\
\hline Possible & Low & Moderate & Moderate & High & High \\
\hline Rare & Low & Low & Low & Moderate & High \\
\hline $\begin{array}{l}\text { Almost } \\
\text { impossible }\end{array}$ & Low & Low & Low & Low & Low \\
\hline
\end{tabular}

Figure 5 Risk matrix example for mining activities used by personnel at an underground mine

There are several examples of risk matrices used in mining geomechanics. For example, Carter (2014) provided an example specific to crown pillar failure (Figure 6). In this context, the empirical scaled span approach was used as a tool for a qualitative or quantitative risk assessment. Joughin et al. (2016) provide another example of a matrix where probability of occurrence and the value of the potential losses are listed (Figure 7). They also acknowledge that risk matrices vary from operation to operation, depending on the level of financial risk tolerance. 


\begin{tabular}{|c|c|c|c|c|c|}
\hline \multirow{2}{*}{$\begin{array}{l}\text { Pillar failure } \\
\text { Likelihood }\end{array}$} & \multicolumn{5}{|c|}{ Consequence severity } \\
\hline & Low & Minor & Moderate & Major & Critical \\
\hline Almost certain & High & Very High & Extreme & Extreme & Extreme \\
\hline Likely & Moderate & High & Very High & Extreme & Extreme \\
\hline Possible & Low & Moderate & High & Extreme & Extreme \\
\hline Unlikely & Low & Low & Moderate & Very High & Extreme \\
\hline Rare & Very Low & Low & Moderate & High & Very High \\
\hline
\end{tabular}

Figure 6 Risk matrix example for crown failure (after Carter 2014)

\begin{tabular}{|c|c|c|c|c|c|}
\hline \multirow{2}{*}{$\begin{array}{l}\text { Probability of } \\
\text { occurrence }\end{array}$} & \multicolumn{5}{|l|}{ Damage loss } \\
\hline & $\begin{array}{l}\text { Insignificant } \\
<\$ 0.01 \mathrm{M}\end{array}$ & $\begin{array}{l}\text { Minor } \\
\$ 0.01 \mathrm{M}-\$ 0.10 \mathrm{M}\end{array}$ & $\begin{array}{l}\text { Moderate } \\
\$ 0.10 \mathrm{M}-\$ 1.0 \mathrm{M}\end{array}$ & $\begin{array}{l}\text { Major } \\
\$ 1 M-\$ 10 M\end{array}$ & $\begin{array}{l}\text { Catastrophic } \\
>\$ 10 \mathrm{M}\end{array}$ \\
\hline Certain & Low & Medium & High & Extreme & Extreme \\
\hline Likely & Low & Medium & High & High & Extreme \\
\hline Possible & Low & Low & Medium & High & High \\
\hline Unlikely & Low & Low & Medium & Medium & High \\
\hline Rare & Low & Low & Low & Medium & Medium \\
\hline
\end{tabular}

Figure 7 Risk matrix example (after Joughin et al. 2016)

Figure 8 is an example matrix used in another mine. It is interesting to note that in this case, the likelihood and consequences ratings ( 1 to 5 ) are multiplied to assign a risk rating. Unlike the process of multiplying probability of occurrence and numerical values of consequence or loss, it is not obvious that multiplying ratings is in fact appropriate.

\begin{tabular}{|c|c|c|c|c|c|}
\hline \multirow[t]{2}{*}{ Likelihood } & \multicolumn{5}{|c|}{ Consequence } \\
\hline & $\begin{array}{l}\text { Low } \\
\text { Rating } 1\end{array}$ & $\begin{array}{l}\text { Minor } \\
\text { Rating } 2\end{array}$ & $\begin{array}{l}\text { Moderate } \\
\text { Rating } 3\end{array}$ & $\begin{array}{l}\text { Major } \\
\text { Rating } 4\end{array}$ & $\begin{array}{l}\text { Extreme } \\
\text { Rating } 5\end{array}$ \\
\hline $\begin{array}{l}\text { Almost certain } \\
\text { Rating } 5\end{array}$ & $\begin{array}{l}\text { Moderate } \\
5\end{array}$ & $\begin{array}{l}\text { Moderate } \\
10\end{array}$ & $\begin{array}{l}\text { High } \\
15\end{array}$ & $\begin{array}{l}\text { Critical } \\
20\end{array}$ & $\begin{array}{l}\text { Critical } \\
25\end{array}$ \\
\hline $\begin{array}{l}\text { Very likely } \\
\text { Rating } 4\end{array}$ & $\begin{array}{l}\text { Low } \\
4\end{array}$ & $\begin{array}{l}\text { Moderate } \\
8\end{array}$ & $\begin{array}{l}\text { High } \\
12\end{array}$ & $\begin{array}{l}\text { High } \\
16\end{array}$ & $\begin{array}{l}\text { Critical } \\
20\end{array}$ \\
\hline $\begin{array}{l}\text { Likely } \\
\text { Rating } 3\end{array}$ & $\begin{array}{l}\text { Low } \\
3\end{array}$ & $\begin{array}{l}\text { Moderate } \\
6\end{array}$ & $\begin{array}{l}\text { Moderate } \\
9\end{array}$ & $\begin{array}{l}\text { High } \\
12\end{array}$ & $\begin{array}{l}\text { High } \\
15\end{array}$ \\
\hline $\begin{array}{l}\text { Unlikely } \\
\text { Rating } 2\end{array}$ & $\begin{array}{l}\text { Low } \\
2\end{array}$ & $\begin{array}{l}\text { Low } \\
4\end{array}$ & $\begin{array}{l}\text { Moderate } \\
6\end{array}$ & $\begin{array}{l}\text { Moderate } \\
8\end{array}$ & $\begin{array}{l}\text { Moderate } \\
10\end{array}$ \\
\hline $\begin{array}{l}\text { Rare } \\
\text { Rating } 1\end{array}$ & $\begin{array}{l}\text { Low } \\
1\end{array}$ & $\begin{array}{l}\text { Low } \\
2\end{array}$ & $\begin{array}{l}\text { Low } \\
3\end{array}$ & $\begin{array}{l}\text { Low } \\
4\end{array}$ & $\begin{array}{l}\text { Moderate } \\
5\end{array}$ \\
\hline
\end{tabular}

Figure 8 Likelihood versus consequence risk matrix example from an underground mine 
Despite their omnipresence, a critical discussion on the limitations and effectiveness of risk matrices as a tool for managing and communicating geomechanical risk seems to be absent. The first concern is the lack of consistency in the design of risk matrices. There are important variations in the number of rows and columns used, the values on the $x$ - and $y$-axes, and the direction of risk scaling within the matrix. All these factors can have a significant impact on the results of the analysis.

Another common, but arguably difficult to defend argument, is that the major benefit from the use of a risk matrix is through the use of the heat map that allows effective communication of the highest risks. A cursory review of the examples in this paper suggests that there is no consistent way of assigning the colours in the heat map. Even with the same organisation, there are significant differences on how risk matrices are colour coded. Figure 5 illustrates another inconsistency where there is no yellow cell to separate a low (green) and high (red) in the disability column. Given the inconsistency on how these colour codes are assigned, it is not evident that risk matrices actually improve communication.

A further inconsistency is how different users assign descriptions of likelihood. As illustrated in the risk matrices reproduced in Figures 5 to 8, there are variations in both description and classes. This is also the case when likelihood is assigned a probability value, as illustrated in Table 1, comparing two approaches. The issue is not which of the two systems is more appropriate but rather their significant differences. If both types of criteria are used within the same organisation, this could clearly result in differing interpretations of the resulting risk, and could result in quite divergent decisions on how to manage a specific geomechanical risk. There is an obvious need for a more consistent codification of verbal and quantitative probability expressions. The work of Reagan et al. (1989) is of interest in that they studied the meanings of 18 verbal probability expressions and the assigned quantitative meanings. A consistent approach is critical in managing geomechanical risk given the existing asymmetry of knowledge between technical and management personnel.

Table 1 Comparison of probability/likelihood assignments for two risk matrix examples

\begin{tabular}{|c|c|c|c|c|c|}
\hline \multicolumn{3}{|c|}{ Joughin et al. (2016) } & \multicolumn{3}{|c|}{ Ontario Ministry of Labour (2017) } \\
\hline $\begin{array}{l}\text { Probability } \\
\text { description }\end{array}$ & Description & Probability & Likelihood & Description & Probability \\
\hline Certain & $\begin{array}{l}\text { The event will occur. } \\
\text { The event occurs } \\
\text { daily }\end{array}$ & $>50 \%$ & $\begin{array}{l}\text { Almost } \\
\text { certain }\end{array}$ & $\begin{array}{l}\text { Unwanted event is } \\
\text { almost certain to } \\
\text { happen in the next } \\
\text { year }\end{array}$ & $>90 \%$ \\
\hline Likely & $\begin{array}{l}\text { The event is likely to } \\
\text { occur. The event } \\
\text { occurs monthly }\end{array}$ & $10-50 \%$ & Very likely & $\begin{array}{l}\text { High probability for } \\
\text { unwanted event to } \\
\text { occur next year }\end{array}$ & $50-90 \%$ \\
\hline Possible & $\begin{array}{l}\text { The event will occur } \\
\text { under some } \\
\text { circumstances. The } \\
\text { event occurs annually }\end{array}$ & $5-10 \%$ & Likely & $\begin{array}{l}\text { It is possible for } \\
\text { unwanted event to } \\
\text { occur next year }\end{array}$ & $20-50 \%$ \\
\hline Unlikely & $\begin{array}{l}\text { The event has } \\
\text { happened elsewhere. } \\
\text { The event occurs } \\
\text { every } 10 \text { years }\end{array}$ & $1-5 \%$ & Unlikely & $\begin{array}{l}\text { Low probability for } \\
\text { unwanted event to } \\
\text { occur next year }\end{array}$ & $5-20 \%$ \\
\hline Rare & $\begin{array}{l}\text { The event may occur } \\
\text { in exceptional } \\
\text { circumstances. The } \\
\text { event has rarely } \\
\text { occurred in the } \\
\text { industry }\end{array}$ & $<1 \%$ & Rare & $\begin{array}{l}\text { Very low probability } \\
\text { for unwanted event } \\
\text { to occur next year }\end{array}$ & $<5 \%$ \\
\hline
\end{tabular}


Finally, the efficiency of a risk matrix to capture the large-scale events or complex problems is also open to question. The main argument in this paper is not that risk matrices are not providing value; rather that there is a need to recognise and assess both their limitations and the way they are employed. Failure to do so may have inadvertent results.

\subsection{Geotechnical review boards}

Several companies have established external geotechnical reviews as a way to mitigate geomechanical risks. In general, these review boards focus on tailings, open pit slope design or the management of seismicity in underground mines. The instigation of a Geotechnical Review Board (GRB) has been either in response to a major event (e.g. slope failure, rockburst damage), or in certain cases, as a proactive measure.

The effectiveness of a GRB is often dictated by how well-defined the scope of the mandate is and how well it is understood by the operation. Another important element in an effective GRB is that the assigned members are not only competent, but they also have the appropriate and complementary skillsets. Baecher and Christian (2003) suggest that board members can be categorised into distinct types:

- Resources: individuals with special knowledge of a problem, technology, site or project.

- Proponents: individuals with particular and strongly argued point of a view.

- Evaluators: individuals with open mind willing to judge objectively the credibility of different hypotheses, points of view or opinions.

- Facilitators: individuals versed in the technical issues who are also willing to lead discussions and manage interactions among other experts.

Baecher and Christian (2003) suggest that a successful board needs to include an evaluator and facilitator with resources and proponents providing technical breadth and balance.

An effective board should challenge all critical elements of design, practice and operation. This implies that the board members are also independent and were not involved in the design process. An external GRB can arguably also provide a mining company or mine operation some safeguards against groupthink. This is the case when members of a cohesive group lose their ability to critically evaluate each other's input work.

\section{Management and communication of risk}

The overall risk-management process advocated in the ISO guidelines (ISO 2018) is well-applicable to the management of geomechanical mining risk. Brown (2012) notes that similar approaches to earlier ISO guidelines have been adopted by other national and international authorities (e.g. Standards Australia 2009). An example of a risk-management process is illustrated in Figure 9. Mining companies are expected to systematically apply procedures to establish the context, assess, treat, monitor, record, report and communicate risk. This is a continued and dynamic process.

From a geomechanical risk perspective, the focus is traditionally on risk assessment that involves identification, analysis and evaluation of risk. It is perhaps appropriate to also note that the results of the risk assessment are best used to inform, rather than dictate decisions, and they are only one of many factors that should be taken into account in reaching a decision. The following sections focus on risk management and communication responsibilities in a mining context. 


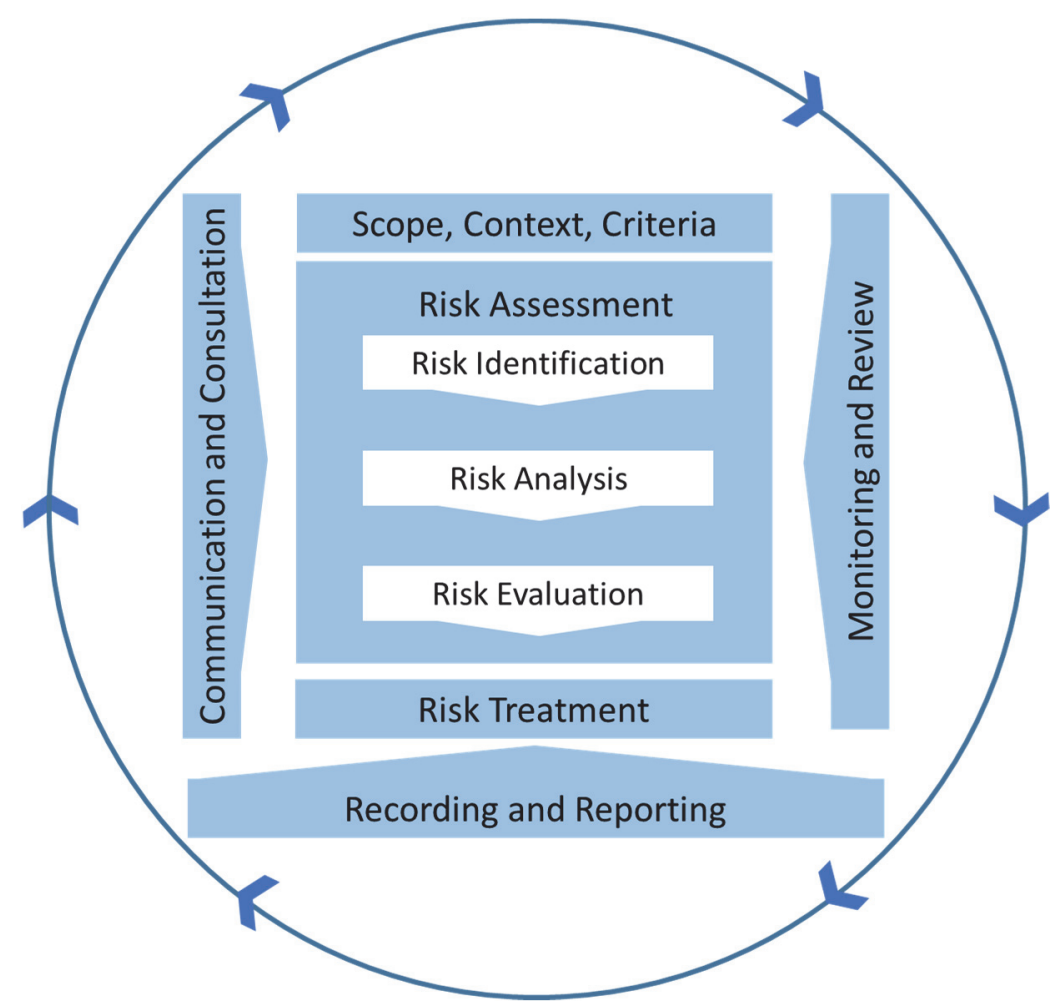

Figure 9 Risk-management process (after ISO 2018)

\subsection{Risk-management responsibilities}

The purpose of risk management is the creation and protection of value. In a mining company, risk-management responsibilities are shared or assigned to different players. In general, geomechanical mining risk is not always consistently communicated within a mining company.

\subsubsection{Board of Directors}

The Board of Directors is generally assigned a risk-oversight role. Geomechanical risk may not be specifically brought to the attention of the board. Examples where it is flagged could be related to major rockbursts that may have significant impact on an operation. It is indicative that geomechanical risk is under the health and safety or technical committees of most mining boards. Risk management is often part of audit committee and its members may not have mining skills.

\subsubsection{Senior management}

Senior management designs and implements processes that respect board's corporate risk strategy and are functioning as directed. It is the responsibility of senior management to instil a culture of risk-adjusted decision-making throughout the organisation and provide guidelines to technical personnel. Finally, senior management inform the board on the company's most material risks, how these risks interrelate, how they affect the company, and how management addresses these risks.

\subsubsection{Mine management}

Mine management is responsible for the day-to-day operation. In a single-asset company there is an overlap between responsibilities of senior corporate and mine management. 


\subsubsection{Technical/engineering}

The main responsibility is to design and construct engineering structures and provide oversight to operations. They employ risk-analysis tools to identify and quantify geomechanical risk. Finally, they provide input to the company risk policy/strategy.

\subsubsection{Operations}

The main emphasis is to implement good practice to ensure the safety of personnel and equipment, and to limit or mitigate risk. It is important to assess whether geomechanical mining risk is important or recognised at the different levels of an operation.

\subsubsection{Regulators and legislators}

There is no clear consensus on the role of regulators and legislators in managing risk. There is a school of thought that argues that regulatory agencies should not be part of the risk-management process, other than requiring that a process is in place. It is the author's opinion that the management of geomechanical risk can be improved if risk reduction is recognised as an opportunity for improving the business, as opposed to a legislative or corporate requirement.

\subsection{Risk appetite and tolerance}

A mining company is expected to address the question of what constitutes acceptable or tolerable risk and define its risk appetite. Although these terms are often used interchangeably, they are often interpreted differently. The reality is that there is no standard or regulated definition of what constitutes acceptable or tolerable risk, or risk appetite. The lack of a standardised approach is reflected in risk-management statements issued by mining companies. They range from one paragraph to multi-page, detailed descriptions.

There is empirical evidence that risk appetite and tolerance is approached differently by junior, single asset mining companies, as compared to intermediate or multi-asset, major companies. It is generally assumed that smaller mining companies are by nature more inclined to take greater risks. On the other hand, a multi-asset mining company can absorb the consequences of a greater risk appetite.

Unacceptable risk is often articulated by mining companies that introduce a zero tolerance approach to all safety issues. 'Tolerable' implies that a certain risk is worth taking and that is being controlled. The concept of risk appetite is useful in aiding decision-makers throughout an organisation, making the necessary trade-offs between company aims, and defining risk tolerance (Quail 2012). A company's risk appetite should be defined by its highest level of leadership and management. For example, it is not up to the ground control or rock mechanics engineer to establish a mine's risk appetite on geomechanical issues such as managing seismicity and meeting production requirements in a deep and high-stress mine.

Quail (2012) suggests that a company's chief executive officer and senior executives establish a target risk appetite for each company objective (i.e. willingness of decisions-makers in the company to place a strategic objective at risk). This process can be facilitated by using an index similar to that reproduced in Table 2 . The assigned rating of each strategic objective can then be plotted in a spider chart such as in Figure 10(a). This plots the risk appetite of an organisation, whereby a larger overall region in the spider chart signifies a greater organisational risk appetite. The executive group should then use the same rating procedure to assess the perceived risk appetite of decision-makers throughout the organisation using examples on how decision-makers make tough decisions. The exhibited appetite region can then be superimposed on the same spider chart as before (Figure 10(b)). A gap between the two areas in the chart would identify a misalignment between target and exhibited risk appetite. Finally, a third step would require the same exercise undertaken throughout the organisation. This would help appreciate how well aligned perception of risk appetite is within the company. For example, in a mining company, this could provide an assessment of how decisionmakers address situations where geomechanical risk and production requirements conflict. 
Table 2 Risk appetite scale (after Quail 2012)

\begin{tabular}{|c|c|c|c|c|c|}
\hline & ting & Philosophy & Tolerance for & Choice & Trade-off \\
\hline & & $\begin{array}{l}\text { Overall risk-taking } \\
\text { philosophy }\end{array}$ & $\begin{array}{l}\text { Willingness to } \\
\text { accept uncertain } \\
\text { outcomes or } \\
\text { period-to-period } \\
\text { variation }\end{array}$ & $\begin{array}{l}\text { When faced with } \\
\text { multiple options, } \\
\text { willingness to select an } \\
\text { option that puts } \\
\text { objectives at risk }\end{array}$ & $\begin{array}{l}\text { Willingness to } \\
\text { trade-off against } \\
\text { achievement of } \\
\text { other objectives }\end{array}$ \\
\hline 5 & Open & Will take justified risks & Fully anticipated & $\begin{array}{l}\text { Will choose option with } \\
\text { highest return; accept } \\
\text { possibility of failure }\end{array}$ & Willing \\
\hline 4 & Flexible & $\begin{array}{l}\text { Will take strongly } \\
\text { justified risks }\end{array}$ & Expect some & $\begin{array}{l}\text { Will choose to put at } \\
\text { risk, but will manage } \\
\text { impact }\end{array}$ & $\begin{array}{l}\text { Willing under } \\
\text { right conditions }\end{array}$ \\
\hline 3 & Cautious & $\begin{array}{l}\text { Preference for safe } \\
\text { delivery }\end{array}$ & Limited & $\begin{array}{l}\text { Will accept if limited } \\
\text { and heavily } \\
\text { out-weighed by } \\
\text { benefits }\end{array}$ & Prefer to avoid \\
\hline 2 & Minimalist & $\begin{array}{l}\text { Extremely } \\
\text { conservative }\end{array}$ & Low & $\begin{array}{l}\text { Will accept only if } \\
\text { essential, and limited } \\
\text { possibility/extent of } \\
\text { failure }\end{array}$ & $\begin{array}{l}\text { With extreme } \\
\text { possibility }\end{array}$ \\
\hline 1 & Averse & $\begin{array}{l}\text { Sacred avoidance of } \\
\text { risk is a core objective }\end{array}$ & Extremely low & $\begin{array}{l}\text { Will select the lowest } \\
\text { risk option, always }\end{array}$ & Never \\
\hline
\end{tabular}

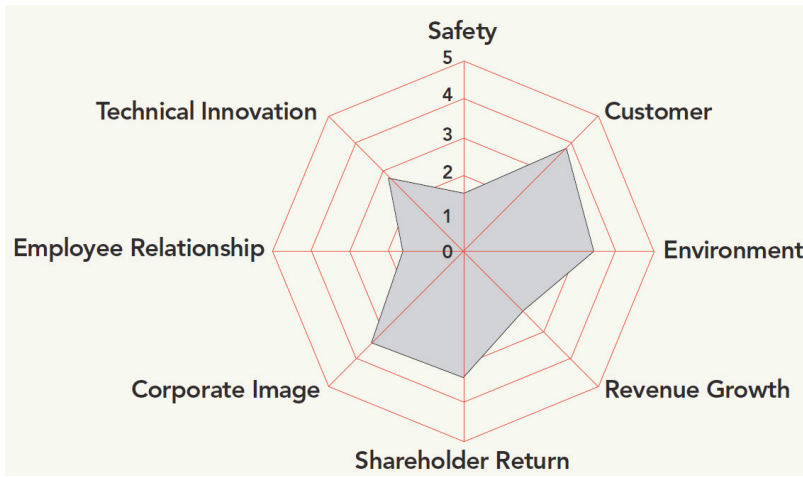

(a)

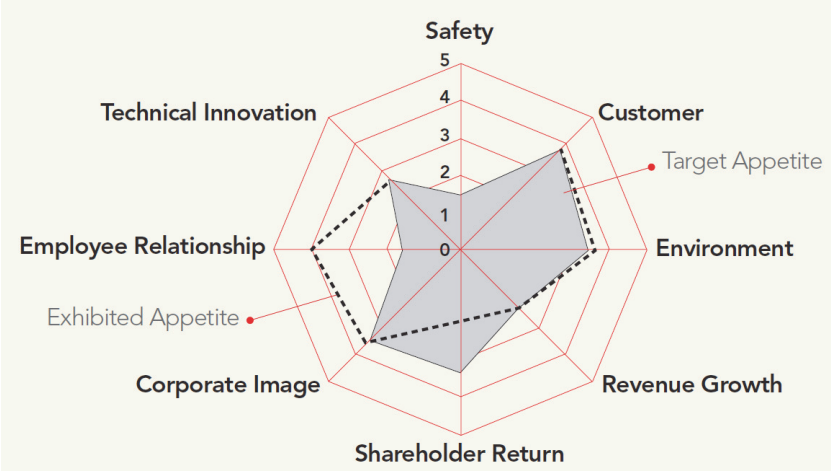

(b)

Figure 10 (a) Target risk appetite; (b) Target versus exhibited risk appetite (after Quail 2012)

Perhaps the most widely used approach to establish risk tolerance is the ALARP approach, 'as low as reasonably practicable', and illustrated in Figure 11 (Health and Safety Executive 2001). In this context, tolerable implies that the risk is worth taking to secure certain benefits and that it is properly controlled. ALARP diagrams are sometimes used to demonstrate that an organisation has done all that is considered to be practical in reducing the level of exposure to a risk.

An application of an ALARP diagram to manage geomechanical risk has been provided by Carter (2014). An ALARP diagram was used, along with the risk matrix in Figure 6, as a decision tool in selecting post-closure usage of a surface crown pillar. In this context, unacceptable would imply that it should not be accessible by the public or the hazard is isolated. ALARP levels would limit access dependent on usage and acceptable would allow free access. 


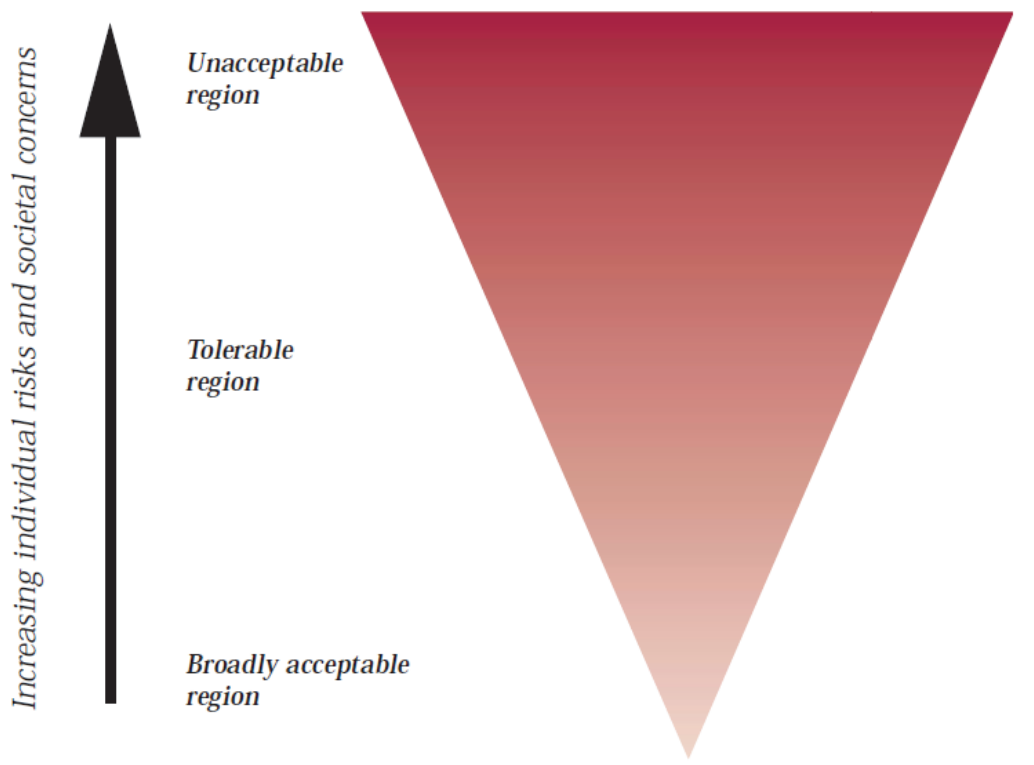

Figure 11 Framework for the tolerability of risk (after Health and Safety Executive 2001)

\subsection{Communicating risk}

Risk communication is an interactive process of exchange of information and opinion among individuals, groups, and organisations or units. Geomechanical issues can range from quality control of ground support and falls of ground to major mine-wide seismic events. The challenge is to be able to communicate all important information and associated risks in a timely fashion without resulting in data overload at different decision levels. A company's risk appetite should be well-understood throughout the organisation in order to avoid grey or inconsistent flow of information. Figure 12 is a conceptual diagram for communicating geomechanical risk within an organisation. There should be well established and understood trigger thresholds to provide guidance on when to communicate a risk to the next decision level. The type and severity of risk and the company's risk appetite dictates what information is transmitted to the next level. Not all geomechanical risk qualifies to reach the board, but at the same time, no level of management appreciates surprises.

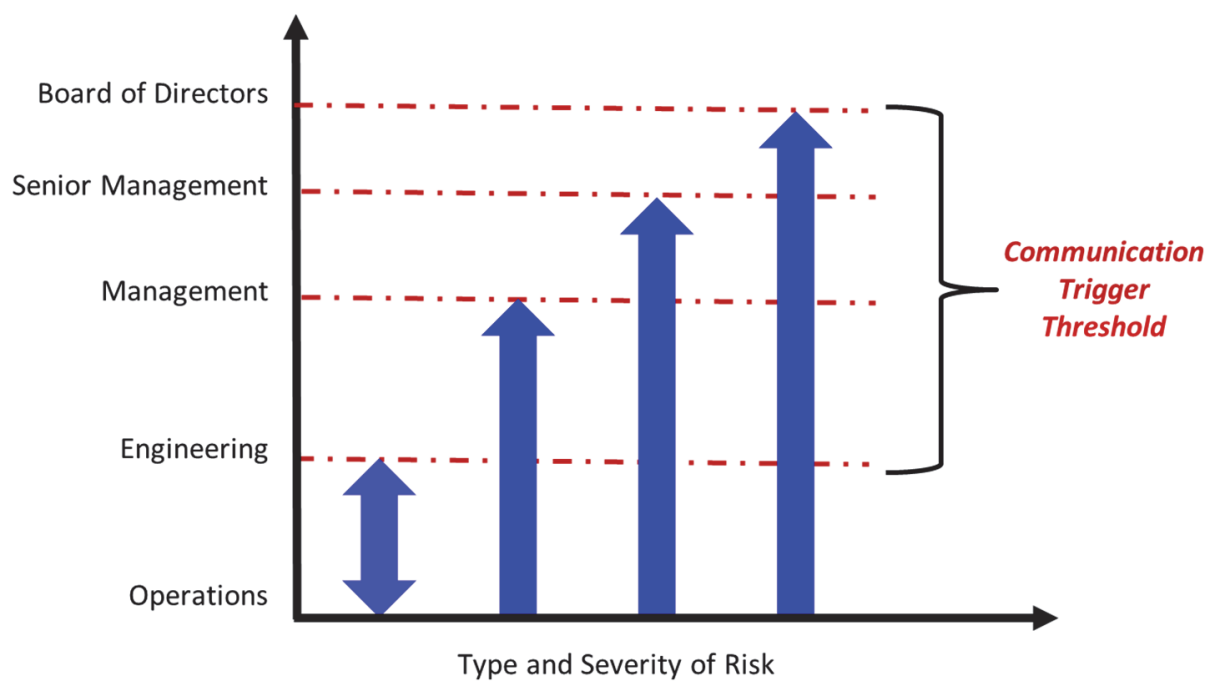

Figure 12 Internal trigger thresholds for communicating geomechanical risk

The introduction of risk-management and communication strategies have undeniably contributed to a safer mining working environment. This is evident in seismically active mines where it is standard practice to employ significant event procedures with well-defined follow-up actions and communication procedures. For 
example, these may include instructions for when to proceed to refuge stations, barricading affected areas, and re-entry protocols. However, the effectiveness of re-entry protocols is controlled by the quality of seismic data and the rock mass response.

As discussed in this paper, there are inherent difficulties in communicating geomechanical risk between the different stakeholders. Risk is subjective and it would appear that some of the management tools are not consistently applied. The quality of constructed risk-management tools does not appear to be questioned. It should also be emphasised that successful geomechanical risk-management and communication strategies require that there are adequate and qualified resources at all levels of the organisation.

Further to internal strategies, it is imperative for mining companies to put in place communication channels with outside stakeholders, such as regulators and the public. It is often a requirement to report to regulators major seismic events that may result in damage, injuries or fatalities. It is now common practice for mining companies to have in place a process identifying who is authorised to speak on behalf of the company as part of their risk-management plan. What has changed in recent years is the need for mining companies to develop and implement social media risk-management plans. These imply that it is necessary to continuously monitor social media and intervene when necessary. Therefore, geomechanical risk has to be well-understood by those responsible for the corporate communication strategy.

\section{Discussion}

In general, there are important challenges in managing geomechanical risk. Engineering analysis and design have to recognise and try to manage sources of error and uncertainty in data and model limitations. As this paper illustrates, there are several ways to describe a decision problem and frame the definition of geomechanical risk. Tversky and Kahneman (1986) have shown that the way a risk is defined can give rise to different preferences on the way it is understood and acted upon. In general, choices involving gains are often risk averse, and choices involving losses are often risk taking.

The interaction between the Board of Directors, management and technical/engineering is not always well-defined, and in certain cases, there is strong reluctance to assign/accept responsibility for risk management. This is further complicated by the asymmetry of knowledge between the different levels within a mining company. There are several opportunities to explore whether a company's risk appetite profile is understood at all levels of the company.

\section{Conclusion}

This admittedly non-exhaustive review of risk management suggests that there are procedures and tools to quantify geomechanical risk. Invariably, an effective strategy includes the following:

- Geomechanical data collection and quantifying uncertainties.

- Risk assessment based on performance and consequence.

- Decision-making which could involve selecting an engineering alternative, mitigating strategies or collecting further information.

An effective risk-management program requires that:

- The risk problem is properly framed and presentation of risk uses consistent terminology.

- The nature and limitations of the risk assessment are clearly set out and understood.

- The quality of the risk assessment is critically reviewed before accepted as a compliance requirement.

- The results of the risk assessment are used to inform rather than to dictate decisions and are only one of the many factors taken into account in reaching a decision.

- Risk is a dynamic process and, consequently, it has to be consistently and continually updated. 
- The management of geomechanical risk can be improved if risk reduction is recognised as an opportunity for improving the business, as opposed to a legislative or corporate requirement.

Geomechanical risk can be minimised, managed, shared, transferred or accepted, but all these processes imply that it is understood. This paper introduces the concept that the management of geomechanical risk is hindered by the asymmetry of knowledge at the various decision levels and inconsistent communication strategies. It is imperative that the quality and performance of risk-assessment strategies are themselves critically evaluated. Failure to do so entails its own risks.

\section{Acknowledgement}

This paper was made possible through multiple interactions over the years with several colleagues and mining companies. The views and opinions expressed in this paper are those of the author and do not necessarily reflect the views of any organisation.

\section{References}

Baecher, GB \& Christian, JT 2003, Reliability and Statistics in Geotechnical Engineering, John Wiley \& Sons Ltd, Chichester.

Bahrani, N \& Hadjigeorgiou, J 2018, 'Influence of stope excavation on drift convergence and support behavior: insights from 3D continuum and discontinuum models', Rock Mechanics and Rock Engineering, vol. 51, pp. 2395-2413.

Brown, ET 2012, 'Risk assessment and management in underground rock engineering-an overview', Journal of Rock Mechanics and Geotechnical Engineering, vol. 4, no. 3, pp. 193-204.

Carter, TG 2014, 'Guidelines for use of the scaled span method for surface crown pillar stability assessment', Proceedings of the 1st International Conference on Applied Empirical Design Methods in Mining, Sociedad Peruana de Geoingenieria.

Dershowitz, WS \& Einstein, HH 1988, 'Characterizing rock joint geometry with joint system models', Rock Mechanics and Rock Engineering, vol. 21, pp. 21-51.

Einstein, HH 1996, 'Risk and risk analysis in rock engineering', Tunnelling and Underground Space Technology, vol. 11, no. 2, pp. $141-155$.

Einstein, HH 2003, 'Uncertainty in rock mechanics and rock engineering - then and now', Proceedings of the 10th ISRM Congress, International Society for Rock Mechanics and Rock Engineering, Lisbon, pp. 281-293.

Fillion, MH \& Hadjigeorgiou, J 2016, 'Implications of collecting additional data for slope design in an open pit operation', The Journal of the Southern African Institute of Mining and Metallurgy, vol. 116, pp. 357-366.

Fillion, MH \& Hadjigeorgiou, J 2017, 'Quantifying the impact of additional laboratory tests on the quality of a geomechanical model'. Rock Mechanics and Rock Engineering, vol. 50, issue 5, pp. 1097-1121.

Fillion, MH \& Hadjigeorgiou, J 2018, 'Recommendations for a quantitative description of joint orientation data', Geotechnical and Geological Engineering, https://doi.org/10.1007/s10706-018-0703-8

Gill, DE, Corthésy, R \& Leite, MH 2005, 'Determining the minimal number of specimens for laboratory testing of rock properties', Engineering Geology, vol. 78, issue 1-2, pp. 29-51.

Gritziotis, G 2015, Final Report Vol. 1: Mining Health, Safety and Prevention Review, Ministry of Labour, Toronto.

Grenon, M \& Hadjigeorgiou, J 2003, 'Drift reinforcement design based on discontinuity network modelling', International Journal Rock Mechanics and Mining Sciences, vol. 40, issue 6, pp. 833-845.

Hadjigeorgiou, J 2012, 'Where do the data come from?', Mining Technology, vol. 121, no. 4, pp. 236-247.

Hadjigeorgiou, J \& Harrison, JP 2011, 'Uncertainty and sources of error in rock engineering, in Q Qian and X Zhou (eds), ISRM Congress of Rock Mechanics, Harmonising Rock Engineering and the Environment, CRC Press, London, pp. 2063-2067.

Hadjigeorgiou, J \& Grenon, M 2017, 'Drift reinforcement design based on Discrete Fracture Network (DFN) modelling, in X-T Feng (ed), Rock Mechanics and Engineering, vol. 4, Taylor \& Francis Group, Milton Park, pp. 123-146.

Health and Safety Executive 2001, Reducing Risks, Protecting People: HSE's Decision-making Process, Health and Safety Executive. ISO 2018, 31000:2018, Risk Management - Guidelines, International Organization for Standardization, Geneva.

Joughin, WC, Muaka, JJM, Mpunzi, P, Sewnun, D \& Wesseloo J 2016, 'A risk-based approach to ground support design', in E Nordlund, TH Jones \& A Eitzenberger (eds.), Proceedings of the Eighth International Symposium on Ground Support in Mining and Underground Construction, Luleå University of Technology, Luleå.

Kiureghian, AD \& Ditlevsen, 0 2009, 'Aleatory or epistemic? Does it matter?', Structural Safety, vol. 31, pp. $105-112$.

Ontario Ministry of Labour 2017, Risk Assessment and Management for Mines and Mining Plants, Ontario Ministry of Labour, Toronto.

Priest, DS \& Brown, ET 1983, 'Probabilistic stability analysis of variable rock slopes', Transactions of the Institute of Mining and Metallurgy, vol. 92, pp. A1-A12.

Quail, R 2012, 'Defining your taste for risk', Corporate Risk Canada, Spring 2012, pp. 25-30.

Reagan, RT, Mosteller, F \& Youtz, C 1989, 'Quantitative meanings of verbal probability expressions', Journal of Applied Psychology, vol. 74, no. 3, pp. 433-442.

Rogers, S, Elmo, D, Beddoes, R \&Dershowitz, W 2009, 'Mine scale DFN modelling and rapid upscaling in geomechanical simulations of large open pits', Proceedings of the International Conference on Large Open Pits.

Stacey TR, Terbrugge PJ \& Wesseloo J 2007, 'Risk as a rock engineering design criterion', Challenges in Deep and High Stress Mining, Y Potvin, TR Stacey \& J Hadjigeorgiou (eds), Australian Centre for Geomechanics, Perth, pp. 19-25. 
Standards Australia 2009, AS/NZS ISO 31000:2009: Risk Management-Principles and Guidelines, Standards Australia, Sydney.

Steffen, OKH 1997, 'Planning of open pit mines on a risk basis', The Journal of the South African Institute of Mining and Metallurgy, vol. 2, pp. 47-56.

Steffen, OKH, Contreras, LF, Terbrugge, PJ \& Venter, J 2008, 'A risk evaluation approach for pit slope design', Proceedings of the 42nd US Rock Mechanics Symposium and 2nd US-Canada Rock Mechanics Symposium, American Rock Mechanics Association, Alexandria.

Terbrugge, PJ, Wesseloo, J, Venter, J \& Steffen, OKH, 2006, 'A risk consequence approach to open pit slope design', The Journal of the South African Institute of Mining and Metallurgy, vol. 106, no. 7, pp. 503-511.

Tversky, A \& Kahneman, D 1986, 'Rational choice and the framing of decisions', The Journal of Business, vol. 59, no. 4, Part 2: The Behavioral Foundations of Economic Theory (Oct., 1986), pp. S251-S278.

Ulusay, R \& Hudson, JA 2007, The Complete ISRM Suggested Methods for Rock Characterization, Testing and Monitoring: 1974-2006, International Society for Rock Mechanics, Lisbon.

Wiles, TD 2006, 'Reliability of numerical modelling predictions', International Journal of Rock Mechanics and Mining Sciences, vol. 43, pp. 454-472. 